\title{
PENERAPAN METODE ACTIVITY BASED COSTING SYTEM SYSTEM DALAM PENENTUAN HARGA POKOK KAMAR PADA GRAHA BIMA INN DI ARJOSARI MALANG
}

\author{
Meyla Nur Vita Sari 1) \\ 1)Institut Agama Islam Sunan Kalijogo Malang \\ 1)melanur43@hotmail.com
}

\begin{abstract}
Abstrak. Latar belakang dari penelitian ini adalah berkembangnya dunia industri jasa terutama jasa penginapan atau perhotelan yang saat ini semakin pesat menjadi salah satu persaingan dalam penjualan kamar. Dalam penentuan harga pokok kamar, banyak industry yang masih belum mengetahui tentang perhitungan harga pokok kamar dengan menggunakan Activity Based Costing Sytem dan masih menggunakan system tradisional. Sehingga penentuan harga kamar tidak sepenuhnya terhitung semua. Oleh karena itu peneliti bertujuan untuk menjelaskan perbedaan antara perhitungan harga pokok kamar secara tradisional dan Activity Based Costing Sytem. Dalam akhir penelitan terjadi selisih harga dikarenakan pada metode Activity Based Costing Sytem, biaya overhead pada masing-masing produk dibebankan pada banyak cost driver. Sehingga dalam metode Activity Based Costing Sytem mampu mengalokasikan biaya aktivitas ke setiap kamar secara tepat berdasarkan konsumsi masing-masing aktivitas.
\end{abstract}

Kata kunci : Activity Based Costing Sytem Sytem, Harga Pokok Kamar Hotel

\begin{abstract}
The background of this research is the development of the service industry, especially lodging or hospitality services, which are currently increasingly becoming one of the competitions in room sales. In determining the cost of a room, many industries still do not know about calculating the cost of a room using the Activity Based Costing System and still using the traditional system. So that the determination of the price of the room is not completely calculated. Therefore, the researcher aims to explain the difference between the traditional room cost calculation and the Activity Based Costing System. At the end of the study there was a price difference because in the Activity Based Costing System method, the overhead costs for each product were charged to many cost drivers. So that the Activity Based Costing System method is able to allocate activity costs to each room appropriately based on the consumption of each activity.
\end{abstract}

Keywords: Activity Based Costing Sytem, Base of Hotel Room Rate

\section{PENDAHULUAN}

Tidak banyak orang yang memahami bahwa harga pokok produk dan jasa merupakan refleksi kemampuan suatu organisasi dalam memproduksi barang dan jasa. Semakin tinggi kemampuan mengelola biaya (cost), maka akan semakin baik produk dan jasa yang ditawarkan 
pada pelanggan baik dari sisi harga maupun kualitas. Pengambilan keputusan yang dilakukan manajemen, mengenai penelusuran informasi biaya akan mempengaruhi pada penetapan harga dan,penambahan atau penghilangan suatu produk atau jasa. Kemampuan untuk menelusuri,biaya tersebut merupakan dasar menghitung biaya dari suatu jasa seperti halnya dalam menghitung biaya barang dari hasil manufaktur. Informasi biaya merupakan,output dari sistem akuntansi biaya yang berhubungan dengan akumulasi biaya, nilai persediaan, dan harga pokok produk. Salah satu perhitungan dalam,menghasilkan biaya produk atau jasa yang tepat yaitu dengan menentukan harga pokok produk ${ }^{1}$.

Activity Based Costing Sytem timbul sebagai akibat kebutuhan manajemen akan informasi biaya per unit sehingga pengelolaan aktivitas dapat dilakukan. Activity Based Costing Sytem merupakan sistem akuntansi biaya yang berbasis aktivitas. Awalnya Activity Based Costing Sytem berorientasi pada penentuan harga per unit yang akurat dalam perusahan manufaktur. Pada tahap perkembangan selanjutnya, Activity Based Costing Sytem tidak lagi difokuskan dalam perhitungan biaya per unit secara akurat, namun dimanfaatkan untuk menghasilkan informasi tentang aktivitas untuk pengurangan biaya melalui pemberdayaan tenaga kerja dalam pengelolaan terhadap aktivitas dan menjadi penyebab timbulnya biaya ${ }^{2}$

Dalam sistem akuntansi tradisional, pembebanan biaya produksi dilakukan atas biaya langsung dan tidak langsung yang berhubungan dengan produk. Secara tradisional, pembebanan biaya atas biaya tidak langsung dilakukan dengan menggunakan dasar pembebanan secara menyeluruh atau per departemen. Hal ini akan menimbulkan banyak masalah karena produk yang dihasilkan tidak dapat mencerminkan biaya yang sebenarnya diserap untuk menghasilkan produk tersebut. Sebagai akibatnya akan muncul produk under costing dan produk over costing.

Inilah yang mendasari dikembangkannya metode Activity Based Costing Sytem. Metode Activity Based Costing Sytem adalah suatu metode perhitungan yang sederhana untuk menentukan harga pokok produk/jasa dengan dasar bahwa aktivitaslah yang menyebabkan

1 Akbar, M. (2011). Analisis Penerapan Metode Activity Based Costing Sytem dalam Penentuan Harga

Pokok kamar Hotel Pada Hotel Coklat Makasar. 26.

2 Mulyadi. Sistem Akauntansi. (Jakarta: Salemba Empat, 2001), 10 
biaya itu timbul, bukan dari produk dan produklah yang mengkonsumsi aktivitas ${ }^{3}$. Dalam Activity Based Costing Sytem biaya-biaya tidak dapat langsung dapat ditentukan melalui aktivitas yang dilaluinya dan biaya untuk masing-masing aktivitas tesebut kemudian dibebankan produk atas dasar konsumsi yang masing-masing produk pada aktivitas.

Konsep sistem Activity Based Costing Sytem merupakan alternatif solusi yang ditempuh oleh perusahaan untuk mendapatkan informasi akuntansi yang relevan dalam keragaman kondisi dan sistem Activity Based Costing Sytem ini menurut harapan, dapat diterapkan pada Graha Bima Inn tentunya disesuaikan dengan situasi dan kondisi manajemen perusahaan. Sehingga manajemen harus mampu mengelola sumber daya dengan melakukan perancangan kembali sistem akuntansi manajemen yang mampu mencerminkan sumber daya dalam aktivitas produk/jasa.

\section{METODE PENELITIAN}

Metode analisis yang digunakan pada penelitian ini adalah metode analisis deskriptif kuantitatif yaitu analisis yang berdasarkan keputusan pada penilaian obyektif yang didasarkan pada model matematika yang dibuat ${ }^{4}$.

Langkah-langkah analisis dalam penelitian ini antara lain :

1. Menghitung harga pokok sewa kamar pada Graha Bima Inn.

2. Melakukan perhitungan harga pokok tarif kamar hotel menggunakan metode ActivityBased Costing System, perhitungan harga pokok produknya terdiri dari biaya overhead yang dialokasikan dengan menggunakan dua cost driver yakni lama hari tamu menginap dan jumlah tamu yang menginap, dilakukan dengan cara berikut :
a. Mengidentifikasi biaya dan aktivitas yang terjadi.
b. Untuk mengidentifikasi biaya pada berbagai aktivitas, pihak hotel perlu mengelompokkan seluruh aktivitas menurut cara bagaimana aktivitas tersebut mengkonsumsi sumber daya.
c. Membebankan biaya sumber daya pada aktivitas.

\footnotetext{
${ }^{3}$ Christine, L. (2008). Aktivitas Hotel dan System Activity Based Costing. Skripsi, 10.

${ }^{4}$ Akbar, M. (2011). Analisis Penerapan Metode Activity Based Costing Sytem dalam Penentuan Harga Pokok kamar Hotel Pada Hotel Coklat Makasar. 26.
} 
d. Metode Activity-Based Costing System menggunakan pemicu biaya untuk membebankan biaya sumber daya dan aktivitas, karena aktivitas memicu timbulnya biaya dari sumber daya yang digunakan dalam operasional perusahaan.

e. Membebankan biaya aktivitas pada produk atau jasa.

f. Pembebanan biaya aktivitas pada produk atau jasa dilakukan melalui dua langkah, yaitu menghitung tarif tiap kelompok aktivitas dan pembebanan biaya pada produk atau jasa.

g. Menentukan tarif per unit cost driver.

h. Membebankan biaya ke produk atau jasa dengan menggunakan tarif cost driver dan ukuran aktivitas.

3. Melakukan perbandingan yang didapat antara harga pokok sewa kamar menurut Graha Bima Inn dengan perhitungan harga pokok sewa kamar menggunakan Activity Based Costing Sytem System.

4. Menarik kesimpulan dari perbandingan perhitungan yang terjadi.

\section{HASIL DAN PEMBAHASAN}

\section{A. Hotel Graha Bima Inn}

Hotel Graha Bima Inn memiliki 7 (tujuh) Jenis kamar diantaranya :

1. Bima Hall yang berjumlah 21 kamar dengan luas sebesar $27,5 \mathrm{~m} 2$

2. Bima Graha, yang berjumlah 8 kamar dengan luas sebesar $42 \mathrm{~m} 2$

3. Guest House, yang berjumlah 16 kamar dengan luas sebesar $27,5 \mathrm{~m} 2$

4. Ken Umang, yang berjumlah 29 kamar dengan luas sebesar $27,5 \mathrm{~m} 2$

5. Ken Dedes, yang berjumlah 30 kamar dengan luas sebesar $27,5 \mathrm{~m} 2$

6. Ken Arok, yang berjumlah 16 kamar dengan luas sebesar $27,5 \mathrm{~m} 2$

7. Pavilliun, yang berjumlah 3 kamar dengan luas sebesar $40 \mathrm{~m} 2$

Untuk harga kamar sudah termasuk pajak dan pelayanan (Tax \& Service) yang dikenakan pihak hotel kepada pelanggan sebesar 21\%. Untuk penambahan Extra Bed dikenakan biaya tambahan Rp. 50.000,-- 
Institut Agama Islam Sunan Kalijogo Malang

P-ISSN 2715-7725 E-ISSN 2721-9496

Volume 3 Nomor 2 Desember 2021

Tabel 1

Room Rate Graha Bima Inn tahun 2019

\begin{tabular}{|c|c|}
\hline Jenis Kamar & Room Rate (Rp.) \\
\hline Bima Hall & 350.000 \\
\hline Bima Graha & 550.000 \\
\hline Guest House & 350.000 \\
\hline Ken Umang & 350.000 \\
\hline Ken Dedes & 300.000 \\
\hline Ken Arok & 350.000 \\
\hline Pavilliun & 450.000 \\
\hline
\end{tabular}

Sumber data Graha Bima Inn 2019

Untuk jumlah kamar tersedia untuk dijual dan jumlah hari tamu menginap disetiap jenis kamar selama tahun 2019 pada Graha Bima Inn dapat dilihat pada tabel berikut.

Tabel 2

Jumlah Kamar Tersedia Untuk Dijual

\begin{tabular}{|l|c|c|}
\hline \multicolumn{1}{|c|}{ Jenis Kamar } & $\begin{array}{c}\text { Jumlah Kamar } \\
\text { (1) }\end{array}$ & $\begin{array}{c}\text { Jumlah Kamar Setahun } \\
\text { (1) } \text { x 365 hari }\end{array}$ \\
\hline Bima Hall / BH & 21 & 7665 \\
\hline Bima Graha / BG & 8 & 2920 \\
\hline Guest House / GH & 16 & 5840 \\
\hline Ken Umang / KU & 29 & 10585 \\
\hline Ken Dedes / KD & 30 & 10950 \\
\hline Ken Arok / KA & 16 & 5840 \\
\hline Pavilliun / PAV & 3 & 1095 \\
\hline Jumlah & $\mathbf{1 2 3}$ & $\mathbf{4 4 8 9 5}$ \\
\hline
\end{tabular}

Sumber data Graha Bima Inn 2019

Untuk jumlah hari hunian kamar Graha Bima Inn selama tahun 2019 dapat dilihat pada tabel berikut.

Tabel 3

Pendapatan Penjualan Jasa Kamar Graha Bima Inn Tahun 2019

\begin{tabular}{|l|l|l|l|}
\hline Jenis Kamar & $\begin{array}{l}\text { Jumlah Kamar } \\
\text { Terjual } \\
(\mathbf{1})\end{array}$ & $\begin{array}{l}\text { Harga Jual } \\
\text { Kamar (Rp.) } \\
\mathbf{( 2 )}\end{array}$ & $\begin{array}{l}\text { Pendapatan } \\
\text { Jasa Kamar (Rp.) } \\
\text { (1) x (2) }\end{array}$ \\
\hline Bima Hall & 6720 & 350.000 & 2.352 .000 .000 \\
\hline Bima Graha & 2781 & 550.000 & 1.529 .550 .000 \\
\hline Guest House & 2195 & 350.000 & 768.250 .000 \\
\hline Ken Umang & 9841 & 350.000 & 3.444 .350 .000 \\
\hline Ken Dedes & 7183 & 300.000 & 2.154 .900 .000 \\
\hline Ken Arok & 1968 & 350.000 & 688.800 .000 \\
\hline Pavilliun & 985 & 450.000 & 433.250 .000 \\
\hline
\end{tabular}


Institut Agama Islam Sunan Kalijogo Malang P-ISSN 2715-7725 E-ISSN 2721-9496

Volume 3 Nomor 2 Desember 2021

Jumlah

31673

2.700 .000

11.381.100.000

Sumber data Graha Bima Inn 2019

Tabel 4

Persentase Pendapatan Penjualan Jasa Kamar Graha Bima Inn Tahun 2019

\begin{tabular}{|c|c|c|c|}
\hline Jenis Kamar & $\begin{array}{c}\text { Pendapatan } \\
\text { Jasa Kamar (Rp.) } \\
\text { (1) }\end{array}$ & $\begin{array}{c}\text { Total Pendapatan } \\
\text { Jasa Kamar (Rp.) } \\
\text { (2) }\end{array}$ & $\begin{array}{c}\text { Persentase } \\
\text { Pendapatan } \\
\text { ((1):(2)) } \times 100 \%\end{array}$ \\
\hline Bima Hall & 2.352 .000 .000 & \multirow{7}{*}{11.381 .100 .000} & $20,67 \%$ \\
\hline Bima Graha & 1.529 .550 .000 & & $13,44 \%$ \\
\hline Guest House & 768.250 .000 & & $6,75 \%$ \\
\hline Ken Umang & 3.444 .350 .000 & & $30,26 \%$ \\
\hline Ken Dedes & 2.154 .900 .000 & & $18,93 \%$ \\
\hline Ken Arok & 688.800 .000 & & $6,05 \%$ \\
\hline Pavilliun & 433.250 .000 & & $3,81 \%$ \\
\hline Jumlah & 11.381 .100 .000 & 11.381 .100 .000 & $100 \%$ \\
\hline
\end{tabular}

Sumber data Graha Bima Inn 2019

Tabel 5

Daftar Biaya Langsung dan Biaya Tidak Langsung (dalam Rp.) Tahun 2019

\begin{tabular}{|l|l|l|l|}
\hline \multicolumn{1}{|c|}{ Jenis Biaya } & \multicolumn{1}{|c|}{ Biaya Langsung } & \multicolumn{1}{c|}{$\begin{array}{c}\text { Biaya Tidak } \\
\text { Langsung }\end{array}$} & \multicolumn{1}{c|}{ Total } \\
\hline Gaji karyawan & 703.800 .000 & 702.627 .693 & 1.406 .427 .693 \\
\hline Makan Karyawan & 142.871 .000 & 145.069 .016 & 287.940 .016 \\
\hline Uniform & 56.870 .000 & 57.744 .922 & 114.614 .922 \\
\hline Laundry Linen & 13.503 .500 & 20.761 .758 & 34.265 .258 \\
\hline Cleaning Supplies & 51.369 .820 & 47.433 .171 & 98.802 .991 \\
\hline Guest supplies & 55.968 .378 & 27.952 .138 & 83.920 .516 \\
\hline Room Aminities & 116.757 .850 & - & 116.757 .850 \\
\hline Printing \& Stationary & 18.250 .000 & 27.950 .000 & 46.200 .000 \\
\hline Internet & - & 5.600 .000 & 5.600 .000 \\
\hline Telephone \& Fax & 3.800 .000 & 22.000 .000 & 25.800 .000 \\
\hline Newspaper \& Magazine & - & 4.800 .000 & 4.800 .000 \\
\hline Decoration & - & 4.503 .450 & 4.503 .450 \\
\hline Transportation & - & 26.000 .000 & 26.000 .000 \\
\hline $\begin{array}{l}\text { Bahan Makanan } \\
\text { Minuman }\end{array}$ & - & 821.700 .349 & 821.700 .349 \\
\hline Kitchen & - & 15.390 .171 & 15.390 .171 \\
\hline Advertising \& Promotion & - & 71.650 .000 & 71.650 .000 \\
\hline Electicity & - & 632.720 .989 & 632.720 .989 \\
\hline Water & - & 39.280 .760 & 39.280 .760 \\
\hline
\end{tabular}


Institut Agama Islam Sunan Kalijogo Malang P-ISSN 2715-7725 E-ISSN 2721-9496

Volume 3 Nomor 2 Desember 2021

\begin{tabular}{|l|l|l|l|}
$\begin{array}{l}\text { Bahan Bakar Generator } \\
\text { Listrik }\end{array}$ & - & 33.928 .000 & 33.928 .000 \\
\hline Penyusutan Gedung & - & 196.750 .000 & 196.750 .000 \\
\hline $\begin{array}{l}\text { Penyusutan Perlengkapan } \\
\text { Hotel }\end{array}$ & - & 99.870 .000 & 99.870 .000 \\
\hline Bulbs and Lamp & - & 6.792 .690 & 6.792 .690 \\
\hline Pemeliharaan Kendaraan & - & 15.000 .000 & 15.000 .000 \\
\hline Pemeliharaan AC dan & - & 5.800 .000 & 5.800 .000 \\
\hline $\begin{array}{l}\text { Perbaikan } \\
\text { Pemeliharaan }\end{array}$ & - & 21.870 .000 & 21.870 .000 \\
\hline Total Pengeluaran & $\mathbf{1 . 1 6 3 . 1 9 0 . 5 4 8}$ & $\mathbf{3 . 0 5 3 . 1 9 5 . 1 0 7}$ & $\mathbf{4 . 2 1 6 . 3 8 5 . 6 5 5}$ \\
\hline
\end{tabular}

\section{A. Perhitungan secaran Konvensional}

Tabel 6

Harga Pokok Produk/Jasa Graha Bima Inn Tahun 2019

\begin{tabular}{|c|c|c|c|c|c|c|c|c|c|}
\hline \multicolumn{3}{|c|}{ Elemen Biaya } & Bima Hall & Bima Graha & Guest House & Ken Umang & Ken Dedes & Ken Arok & Pavilliun \\
\hline \multicolumn{10}{|c|}{ Biaya Langsung } \\
\hline $20,67 \%$ & $\mathrm{x}$ & 1.163 .190 .548 & 240.431 .486 & & & & & & \\
\hline $13,44 \%$ & $\mathrm{x}$ & 1.163 .190 .548 & & 156.332 .810 & & & & & \\
\hline $6,75 \%$ & $\mathrm{x}$ & 1.163 .190 .548 & & & 78.515 .362 & & & & \\
\hline $30,26 \%$ & $\mathrm{x}$ & 1.163 .190 .548 & & & & 351.981 .460 & & & \\
\hline $18,93 \%$ & $\mathrm{x}$ & 1.163 .190 .548 & & & & & 220.191 .971 & & \\
\hline $6,05 \%$ & $\mathrm{x}$ & 1.163 .190 .548 & & & & & & 70.373 .028 & \\
\hline $3,81 \%$ & $\mathrm{x}$ & 1.163 .190 .548 & & & & & & & 44.317 .560 \\
\hline \multicolumn{10}{|c|}{ Biaya Tak Langsung } \\
\hline $20,67 \%$ & $\mathrm{x}$ & 3.053 .195 .107 & 631.095 .429 & & & & & & \\
\hline $13,44 \%$ & $\mathrm{x}$ & 3.053.195.107 & & 410.349 .422 & & & & & \\
\hline $6,75 \%$ & $\mathrm{x}$ & 3.053 .195 .107 & & & 206.090 .670 & & & & \\
\hline $30,26 \%$ & $\mathrm{x}$ & 3.053.195.107 & & & & 923.896 .839 & & & \\
\hline $18,93 \%$ & $\mathrm{x}$ & 3.053 .195 .107 & & & & & 577.969 .834 & & \\
\hline $6,05 \%$ & $\mathrm{x}$ & 3.053 .195 .107 & & & & & & 184.718 .304 & \\
\hline $3,81 \%$ & $\mathrm{x}$ & 3.053.195.107 & & & & & & & 116.326 .734 \\
\hline \multicolumn{3}{|c|}{ HPP } & 871.526 .915 & 566.682 .232 & 284.606 .032 & 1.275.878.299 & 798.161 .804 & 255.091 .332 & 160.644 .293 \\
\hline \multicolumn{3}{|c|}{ Jumlah Kamar Terjual } & 6720 & 2781 & 2195 & 9841 & 7183 & 1968 & 985 \\
\hline \multicolumn{3}{|c|}{ Harga Pokok Kamar } & 129.692 & 203.769 & 129.661 & 129.649 & 111.118 & 129.620 & 163.091 \\
\hline
\end{tabular}


Institut Agama Islam Sunan Kalijogo Malang

P-ISSN 2715-7725 E-ISSN 2721-9496

Volume 3 Nomor 2 Desember 2021

\section{B. Perhitungan secara ACTIVITY BASED COSTING SYTEM System}

Tabel 7

Perincian Biaya Langsung Yang Dialokasikan ke Tiap Jenis Kamar Graha Bima Inn Tahun 2019

\begin{tabular}{|c|c|c|c|c|c|c|c|}
\hline \multirow{2}{*}{$\begin{array}{c}\text { Biaya Langsung } \\
\text { Room Dept. }\end{array}$} & \multicolumn{7}{|c|}{ Persentase Alokasi Kamar } \\
\hline & $\begin{array}{l}\text { Bima Hall } \\
(17,07 \%)\end{array}$ & $\begin{array}{c}\text { Bima Graha } \\
(6,50 \%)\end{array}$ & $\begin{array}{c}\text { Guest House } \\
(13,01 \%)\end{array}$ & $\begin{array}{l}\text { Ken Umang } \\
(23,58 \%)\end{array}$ & $\begin{array}{l}\text { Ken Dedes } \\
(24,39 \%)\end{array}$ & $\begin{array}{l}\text { Ken Arok } \\
(13,01 \%)\end{array}$ & $\begin{array}{l}\text { Pavilliun } \\
(2,44 \%)\end{array}$ \\
\hline Gaji Karyawan & 120.138 .660 & 45.747 .000 & 91.564 .040 & 165.956 .040 & 171.656 .820 & 91.564 .380 & 17.172 .720 \\
\hline Makan Karyawan & 24.388 .080 & 9.286 .615 & 18.857 .517 & 33.688 .982 & 34.846 .237 & 18.587 .517 & 3.486 .052 \\
\hline Uniform & 9.707 .709 & 3.696 .550 & 7.398 .787 & 13.409 .946 & 13.870 .593 & 7.398 .787 & 1.387.628 \\
\hline $\begin{array}{c}\text { Total Biaya } \\
\text { Langsung }\end{array}$ & 154.234 .449 & 58.730 .165 & 117.550 .684 & 213.054.968 & 220.373 .650 & 117.550 .684 & 22.046 .400 \\
\hline
\end{tabular}

Tabel 8

Cost Pool Dan Cost driver

\begin{tabular}{|c|c|}
\hline Cost Pool & Cost driver \\
\hline Unit level Activity: & \\
\hline Pool I & \\
\hline Aktivitas penginapan & Jumlah kamar terjual \\
\hline Aktivitas laundry & Jumlah kamar terjual \\
\hline Aktivitas listrik & Jumlah kamar terjual \\
\hline Aktivitas air & Jumlah kamar terjual \\
\hline Pool II & \\
\hline Aktivitas Konsumsi & Jumlah tamu menginap \\
\hline Facility Level Activity & \\
\hline Pool III & Jumlah kamar tersedia \\
\hline Aktivitas pemasaran & \\
\hline Pool IV & Jumlah luas lantai \\
\hline Aktivitas pemeliharaan & Jumlah luas lantai \\
\hline Aktivitas penyusutan & \\
\hline Pool V & Jumlah jam kerja \\
\hline Aktivitas penggajian karyawan & \\
\hline
\end{tabular}

Tabel 9

Tarif Cost Pool

\begin{tabular}{|c|c|c|c|}
\hline Cost Pool & $\begin{array}{c}\text { Total Cost Pool } \\
\text { (Rp.) } \\
\text { (1) }\end{array}$ & $\begin{array}{c}\text { Cost Drive } \\
\text { (2) }\end{array}$ & $\begin{array}{c}\text { Tarif Cost } \\
\text { Pool (Rp.) } \\
(\mathbf{1}):(2)\end{array}$ \\
\hline Cost Pool I & 661.157 .397 & 31.673 & 20.874 \\
\hline Cost Pool II & 1.578 .450 .000 & 63.138 & 25.000 \\
\hline
\end{tabular}


Institut Agama Islam Sunan Kalijogo Malang

P-ISSN 2715-7725 E-ISSN 2721-9496

Volume 3 Nomor 2 Desember 2021

\begin{tabular}{|c|c|c|c|}
\hline Cost Pool III & 42.990 .000 & 44.895 & 958 \\
\hline Cost pool IV & 207.649 .614 & 3.536 & 58.724 \\
\hline Cost Pool $\boldsymbol{V}$ & 543.264 .978 & 162.240 & 3.349 \\
\hline
\end{tabular}

Tabel 10

Harga Pokok Kamar Bima Hall

\begin{tabular}{|c|c|c|c|c|}
\hline No. & Cost Pool & $\begin{array}{c}\text { Tarif Cost } \\
\text { Pool }\end{array}$ & Cost driver & Total (Rp.) \\
\hline 1. & Cost Pool I & 20.874 & 6.720 & $140.273 .280,00$ \\
\hline 2. & Cost Pool II & 25.000 & 13.490 & $337.250 .000,00$ \\
\hline 3. & Cost Pool III & 958 & 7.665 & $7.343 .070,00$ \\
\hline 4. & Cost pool IV & 58.724 & 578 & $33.942 .472,00$ \\
\hline 5. & Cost Pool V & 3.349 & 27.456 & $91.950 .144,00$ \\
\hline \multicolumn{3}{|c|}{ Total Biaya Tidak Langsung } & $\mathbf{6 1 0 . 7 5 8 . 9 6 6 , 0 0}$ \\
\hline \multicolumn{3}{|c|}{ Total Biaya Langsung } & $153.601 .970,00$ \\
\hline \multicolumn{3}{|c|}{ Total Biaya Untuk Kamar Bima Hall } & $\mathbf{7 6 4 . 3 6 0 . 9 3 6 , 0 0}$ \\
\hline \multicolumn{3}{|c|}{ Jumlah Kamar Terjual } \\
\hline
\end{tabular}

Tabel 11

Harga Pokok Kamar Bima Graha

\begin{tabular}{|c|l|l|l|l|}
\hline No. & Cost Pool & $\begin{array}{c}\text { Tarif } \text { Cost } \\
\text { Pool }\end{array}$ & Cost driver & Total (Rp.) \\
\hline 1. & Cost Pool I & 20.874 & 2.781 & $58.050 .594,00$ \\
\hline 2. & Cost Pool II & 25.000 & 5.590 & $139.750 .000,00$ \\
\hline 3. & Cost Pool III & 958 & 2.920 & $2.797 .360,00$ \\
\hline 4. & Cost pool IV & 58.724 & 336 & $19.731 .264,00$ \\
\hline 5. & Cost Pool V & 3.349 & 9.984 & $33.436 .416,00$ \\
\hline \multicolumn{2}{|l|}{ Total Biaya Tidak Langsung } & $\mathbf{2 5 3 . 7 6 5 . 6 3 4 , 0 0}$ \\
\hline
\end{tabular}

Tabel 12

Harga Pokok Guest House

\begin{tabular}{|c|l|l|l|l|}
\hline No. & Cost Pool & $\begin{array}{l}\text { Tarif Cost } \\
\text { Pool }\end{array}$ & Cost driver & Total (Rp.) \\
\hline 1. & Cost Pool I & 20.874 & 2.195 & $45.818 .430,00$ \\
\hline 2. & Cost Pool II & 25.000 & 4.523 & $113.075 .000,00$ \\
\hline 3. & Cost Pool III & 958 & 5.840 & $5.594 .720,00$ \\
\hline 4. & Cost pool IV & 58.724 & 440 & $25.838 .560,00$ \\
\hline 5. & Cost Pool V & 3.349 & 19.968 & $66.872 .832,00$ \\
\hline
\end{tabular}


Institut Agama Islam Sunan Kalijogo Malang

P-ISSN 2715-7725 E-ISSN 2721-9496

Volume 3 Nomor 2 Desember 2021

\begin{tabular}{|l|l|}
\hline Total Biaya Tidak Langsung & $\mathbf{2 5 7 . 1 9 9 . 5 4 2 , 0 0}$ \\
\hline Total Biaya Langsung & $153.601 .970,00$ \\
\hline Total Biaya Untuk Kamar Guest House & $\mathbf{4 1 0 . 8 0 1 . 5 1 2 , 0 0}$ \\
\hline Jumlah Kamar Terjual & 6720 \\
\hline Harga Pokok Kamar Standard & $\mathbf{6 1 . 1 3 1 , 1 8}$ \\
\hline
\end{tabular}

Tabel 13

Harga Pokok Ken Umang

\begin{tabular}{|l|l|l|l|l|}
\hline No. & Cost Pool & $\begin{array}{l}\text { Tarif Cost } \\
\text { Pool }\end{array}$ & Cost driver & Total (Rp.) \\
\hline 1. & Cost Pool I & 20.874 & 9.841 & $205.421 .034,00$ \\
\hline 2. & Cost Pool II & 25.000 & 19.895 & $497.375 .000,00$ \\
\hline 3. & Cost Pool III & 958 & 10.585 & $10.140 .430,00$ \\
\hline 4. & Cost pool IV & 58.724 & 798 & $46.861 .752,00$ \\
\hline 5. & Cost Pool V & 3.349 & 39.936 & $133.745 .664,00$ \\
\hline Total Biaya Tidak Langsung & $\mathbf{8 9 3 . 5 4 3 . 8 8 0 , 0 0}$ \\
\hline
\end{tabular}

Tabel 14

Harga Pokok Kamar Ken Dedes

\begin{tabular}{|c|c|c|c|c|}
\hline No. & Cost Pool & $\begin{array}{l}\text { Tarif Cost } \\
\text { Pool }\end{array}$ & Cost driver & Total (Rp.) \\
\hline 1. & Cost Pool I & 20.874 & 7.183 & $149.937 .942,00$ \\
\hline 2. & Cost Pool II & 25.000 & 14.652 & $366.300 .000,00$ \\
\hline 3. & Cost Pool III & 958 & 10.950 & $10.490 .100,00$ \\
\hline 4. & Cost pool IV & 58.724 & 825 & $48.447 .300,00$ \\
\hline 5. & Cost Pool V & 3.349 & 39.936 & $133.745 .664,00$ \\
\hline Total Biaya Tidak Langsung & $\mathbf{7 0 8 . 9 2 1 . 0 0 6 , 0 0}$ \\
\hline
\end{tabular}


Institut Agama Islam Sunan Kalijogo Malang

P-ISSN 2715-7725 E-ISSN 2721-9496

Volume 3 Nomor 2 Desember 2021

Tabel 15

Harga Pokok Kamar Ken Arok

\begin{tabular}{|l|l|l|l|l|}
\hline No. & Cost Pool & $\begin{array}{l}\text { Tarif } \\
\text { Pool }\end{array}$ & Cost & Total (Rp.) \\
\hline 1. & Cost Pool I & 20.874 & 1.968 & $41.080 .032,00$ \\
\hline 2. & Cost Pool II & 25.000 & 3.982 & $99.550 .000,00$ \\
\hline 3. & Cost Pool III & 958 & 5.840 & $5.594 .720,00$ \\
\hline 4. & Cost pool IV & 58.724 & 440 & $25.838 .560,00$ \\
\hline 5. & Cost Pool V & 3.349 & 19.968 & $66.872 .832,00$ \\
\hline
\end{tabular}

Tabel 16

Harga Pokok Kamar Pavilliun

\begin{tabular}{|c|c|c|c|c|}
\hline No. & Cost Pool & $\begin{array}{l}\text { Tarif } \quad \text { Cost } \\
\text { Pool }\end{array}$ & Cost driver & Total (Rp.) \\
\hline 1. & Cost Pool I & 20.874 & 985 & $20.560 .890,00$ \\
\hline 2. & Cost Pool II & 25.000 & 1.004 & $25.100 .000,00$ \\
\hline 3. & Cost Pool III & 958 & 1.095 & $1.049 .010,00$ \\
\hline 4. & Cost pool IV & 58.724 & 120 & $7.046 .880,00$ \\
\hline 5. & Cost Pool V & 3.349 & 4.992 & $16.718 .208,00$ \\
\hline \multicolumn{4}{|c|}{ Total Biaya Tidak Langsung } & 70.474.988,00 \\
\hline \multicolumn{4}{|c|}{ Total Biaya Langsung } & $153.601 .970,00$ \\
\hline \multicolumn{4}{|c|}{ Total Biaya Untuk Kamar Pavilliun } & $224.076 .958,00$ \\
\hline \multicolumn{4}{|c|}{ Jumlah Kamar Terjual } & 6720 \\
\hline \multicolumn{4}{|c|}{ Harga Pokok Kamar Standard } & $33.344,79$ \\
\hline
\end{tabular}

\section{Perbandingan Perhitungan Harga Pokok Produk/Jasa antara Sistem Konvensional} dengan Activity Based Costing Sytem System

Dari hasil perhitungan harga pokok yang digunakan oleh Graha Bima Inn terlihat adanya perbedaan hasil perhitungan harga pokok konvensional dan hasil perhitungan harga pokok Activity Based Costing Sytem System. Perbedaan tersebut dapat dilihat pada tabel di bawah ini : 


\begin{tabular}{|c|c|c|c|}
\hline \multicolumn{4}{|c|}{$\begin{array}{c}\text { Tabel 17 } \\
\text { Perbandingan Harga Pokok Kamar } \\
\text { Sistem Konvensional Dan Sistem Activity Based Costing Sytem }\end{array}$} \\
\hline Jenis Kamar & $\begin{array}{c}\text { Harga Pokok Kamar } \\
\text { Sistem Tradisional } \\
\text { (Rp.) }\end{array}$ & $\begin{array}{c}\text { Harga Pokok Kamar } \\
\text { Sistem Activity Based } \\
\text { Costing Sytem } \\
\text { (Rp.) }\end{array}$ & $\begin{array}{l}\text { Selisih } \\
\text { (Rp.) }\end{array}$ \\
\hline Bima Hall & 129.692 & 113.744 & 15.948 \\
\hline Bima Graha & 203.769 & 146.482 & 57.287 \\
\hline Guest House & 129.661 & 187.153 & (57.492) \\
\hline Ken Umang & 129.649 & 106.406 & 23.243 \\
\hline Ken Dedes & 111.118 & 120.078 & $(8.960)$ \\
\hline Ken Arok & 129.620 & 199.460 & $(69.840)$ \\
\hline Pavilliun & 163.091 & 227.489 & (64.398) \\
\hline
\end{tabular}

Dari perhitungan diatas, dapat diketahui perbedaan atau selisih dari setiap jenis kamar di Graha Bima Inn. Dari hasil yang diperoleh dapat dibandingkan selisih harga pokok kamar yang telah ditentukan manajemen Graha Bima Inn dengan hasil perhitungan menggunakan pendekatan Activity Based Costing Sytem. Untuk metode activity based costing sytem pada kamar Bima Hall,Bima Graha dan Ken Umang memberikan hasil perhitungan yang lebih kecil daripada harga pokok kamar yang telah ditentukan oleh pihak manajemen Graha Bima Inn. Yaitu dengan selisih harga untuk kamar Bima Hall sebesar Rp. 15.948, kamar Bima Graha Rp. 57.287 dan Ken Umang sebesar Rp. 23.243.

Terjadinya selisih harga dikarenakan pada metode Activity Based Costing Sytem, biaya overhead pada masing-masing produk dibebankan pada banyak cost driver. Sehingga dalam metode Activity Based Costing Sytem mampu mengalokasikan biaya aktivitas ke setiap kamar secara tepat berdasarkan konsumsi masing-masing aktivitas. Sehingga metode Activity Based Costing Sytem lebih baik digunakan dalam keputusan membuat harga pokok kamar. 


\section{PENUTUP}

\section{Kesimpulan dan saran}

Berdasarkan hasil penelitian dan pembahasan yang dilakukan oleh penulis dapat ditarik kesimpulan Bahwa penggunaan metode Activity Based Costing Sytem dalam perhitungan harga pokok kamar menghasilkan harga pokok kamar yang akurat, karena biaya-biaya yang terjadi dibebankan pada produk atas dasar aktivitas dan sumber daya yang dikonsumsikan oleh produk dan juga menggunakan dasar lebih dari satu cost driver atau unsur - unsur biaya yang terlibat dalam perhitungan harga pokok produk/ jasa perusahaan

Dengan menggunakan metode Activity Based Costing Sytem System perusahaan dapat mengendalikan biaya lebih baik karena metode Activity Based Costing Sytem System merupakan sistem analisis biaya berbasis aktivitas untuk memenuhi kebutuhan manajemen dalam pengambilan keputusan, baik yang bersifat strategik maupun operasional 


\section{AL-IOTISHOD}

Institut Agama Islam Sunan Kalijogo Malang

Juгnal Ehonomi รuагіal

P-ISSN 2715-7725 E-ISSN 2721-9496

Volume 3 Nomor 2 Desember 2021

\section{DAFTAR PUSTAKA}

Akbar, M. (2011). Analisis Penerapan Metode Activity Based Costing Sytem dalam Penentuan Harga Pokok kamar Hotel Pada Hotel Coklat Makasar. 26.

Christine, L. (2008). Aktivitas Hotel dan System Activity Based Costing. Skripsi, 10.

Mulyadi. (2001). Sistem Akauntansi. Jakarta: Salemba Empat.

Purwaji, A. W. (2016). Akuntansi Biaya. Jakarta: Salemba Empat. 